boniferous limestone rocki appears even under the mass of Ararat, and has drawn the interence from his wanderings in that region, that in the beginning of the Upper Carboniferous Limestone period a great continental upheaval took place during which the Armenian region received its first outlines. The land thus raised he believes to have remained above water until, in the course of the Cretaceous period, it so far sank as to become an island, and continued in this condition even into Pliocene times, when the whole of that region became involved in another vast continental upheaval to which the final modelling of the Armenian highlands was due. These great terrestrial movements were accompanied by the outbreak of volcanic action. Abich regards the diabase, diorite, and porphyry rocks as having been abundantly erupted during the Jurassic period and to have played an important part in the formation of the mountain masses, especially in the Lower Caucasus. To late Tertiary times, however, belong the trachytic and doleritic lavas which have been poured forth on so colossal a scale as to form such mountains as Elbruz, Kasbek, Ala Cöz, and the two Ararats.

In Mr. Bryce's recently published volume (to which attention has already been drawn in NATUKE) we have a record of the latest and probably the most daring ascent of Mount Ararat. The ugh not a profesed geologist be has had a geological training, and has seen much of many lands, alike in the Old World and in the New. It was not to make out any obscure point in the structure of Ararat that he bent his steps towards that little known mountain. But he had climbed many a peak in Europe, and he no doubt longed to set foot upon the high places of another continent. So he made a pilgrimage to the heights of Armenia, with no theught, however, of writing a book about his journey. The volume he has just putlished has been partly wrung from him by the importunity of friends, who reasonably supposed that the world might be as much interested as they in knowing more about Ararat. In its charmingly iresh and graphic pages one gets such a living picture of the mountain as cannot be gained from any of the geological memoirs. From long experience of mountain climbing his eyes are so keen and so trained, while his per is so facile and vivid that we can mount with him as he gces warily over each lava-current, rubbish-cone, and snow.slope. We feel the sharp thin air of the mountain as it blows through his narrative. We join in his quiet chuckle as he halts at a solitary piece of wood far up on the cone and irreverently detaches a fragment for the inspection of those who cannot personally discover whether the true ark still rests on the top of Ararat. And we can sympathise with his awe as he stood among the clouds alone on the summit of the mysterious mountain. It is not for any new scientific facts so inuch as for the vivid sketch of the general aspect of the huge volcanic mass that his book has an interest to geologists.

A vignette of Ararat forms the frontispiece of the volume, which is here reproduced. In the middle distance is shown the alluvial plain of the Araxes. Below the snowy cone and icy cliffs of the Greater Ararat a deep cleft or recess appears with huge cliffs somewhat like the Val del Bove of Etna, and no doubt due to some of the volcanic explosions of the mountain. On the skyline of this slope, towards the base of the larger cone, some of the late cinder-cones and craters appear. Some of these are still so fresh and perfect that they look as if they had been active only the other day and might blaze forth again to-morrow. The graceful outline of the Lesser Ararat rises on the left.

ARCH. GEIKIE

\section{AGE OF THE SUN IN RELATION TO EVOLUTION}

$\mathrm{NE}$ of the most formidable objections to the theory of evolution is the enormous lensth of time which it demands. On this point Prof. Hackel, one of the highest authorities on the subject, in his "History of Creation," has the follcwing :-- Darwin's theory, as well that of Lyell, renders the assumption of immense periods absolutely necessary. . . If the theory of development be true at all there must certainly have elapsed immense periods, utterly inconceivable to us, during which the gradual historical development of the animal and vegetable proceeded by the slow transformation of species.. the periods during which species originated by gradual transmutation, must not be calculated by single centuries, but by hundreds and by millions of centuries. Every process of development is the more intelligible the longer it is assumed to last."

There are few evolutionists, I presume, who will dispute the accuracy of these statements; but the question arises, does physical science permit the assumption of such enormous periods? We shall now consider the way in which Prof. Haeckel endeavours to answer this question and to meet the obj ctions urged against the enormous lapse of time assumed for evolution.

"I beg leave to remark," he says, "that we have not a single rational ground for conceiving the time requisite to be limited in any way. . . It is absolutely impossible to see what can in any way limit us in assuming long periods of time. . . . From a strictly philosophical point of view it makes no difference whether we hypothetically assume for this process ten millions or ten thousand millions of years. . . In the same way as the distances between the different planetary systems are not calculated by miles but by Sirius-distances, each of which comprises millions of miles, so the organic history of the earth must not be calculated by thousands of years, but by palzentolegical or geological periods, each of which comprises many thousands of years, and perhaps milions or milliards of thousands of years."

Statements more utterly opposed to the present state of modern science on this subject could hardly well te made. Not only have physicists fixed a limit to the extent of time available to the evolutionist, but they have fixed it within very narrow boundaries.

Every one will admit that the organic history of our globe must have been limited by the agre of the sun's heat. The extent of time that the evolutionist is allowe $d$ to assume depends, therefore, on the answer to the question, What is the age of the sun's heat? And this again depends on the ulterior question, From what source has he derived his energy? The sun is losing heat at the enormous rate of 7,000 horse-power on every square foot of surface. And were it composed of coal its combustion would not maintain the present rate of radiation for 5,000 years. Combustion, therefore, cannot be the origin of the heat.

Gravitation is now almost universally appealed to as the only conceivable source from which the sun could have obtained his energy. The contraction theory advocated by Helmholtz is the one generally accepted, but the total amount of work performed by gravitation in the condensaticn of the sun from a nebulous mass to its present size could only have afforded twenty million years' heat at the present rate of radiation. On the assumption that the sun's density increases towards the centre, a few additional million years' heat might be obtained. But on every conceivable supposition gravitation could not have afforded more than tuenty or thirty million years' heat.

Prof. Haeckel may make any assumption he chooses about the age of the sun, but he must not do so in regard to the age of the sun's heat. One who believes it inconceivable that matter can either be created or annihilated may be allowed to maintain that the sun existed from all eternity, but he cannot be permitted to assume that our luminary has been losing heat from all eternity.

If $20,000,000$ or $30,000,000$ years do not suffice for the evolution theory, then either that or the gravitation theory of the origin of the sun's heat will have to be abandoned.

In a former paper (Quarterly fournal of Science for 
July, $18 ; 7$ ) I have proved from geological evidence that the antiquity of our habitable globe must be at least three times greater than it could possibly be had the sun derived its heat simply from the condensation of its mass. This proves that the gravitation theory of the origin of the sun's heat is as irreconcilable with geological facts as it is, accorcling to Hacckel, with those of evolution, and that there must have been some other source, in addition, a! least, to gravity, from which the sun derived his store of energy.

That other source is not so inconceivable as has been assumed, for it is quite conceivable that the nebulous mass from which the sun was formed by condensation might have been possessed of an original store of heat previous to condensation. And this excessive temperature may be the reason why the mass existed in a nebulous or rarefied condition. Now if the mass were originally in a heated condition then in condensing it would have to part not merely with the heat of condensation, but also with the heat it originally possessed.

The question then arises-By what means could the nebulous mass have become incandescent? From what source could the heat have been obtained? The dynamical theory of heat affords, as was shown several years ago (Phil. Mag. for May, 1868), an easy answer to this question. The answer is that the energy in the form of heat possessed by the mass may have been derived from motion in space. Two bodies, each one-half the mass of the sun, moving directly towards each other with a velocity of 476 miles per second, would, by their concussion, generate in a single moment $50,000,000$ years' heat. For two bodies of that mass, moving with a velocity of 476 miles per second, would possess $4,149 \times 10^{38}$ footpounds of kinetic energy, and this, converted into heat by the stoppage of their motion, would give out an amount of heat which would cover the present rate of the sun's radiation for a period of $50,000,000$ years.

There is nothing very extraordinary in the velocity which we have found would be required to generate the $50,000,000$ years' heat in the case of the two supposed bodies. A comet having an orbit extending to the path of the planet Neptune, approaching so near the sun as to almost graze his surface in passing, would have a velo ity of about 390 miles per second, which is within eighty-six niles of that required.

It must be borne in mind, however, that the 476 miles per second is the velocity at the moment of collision. But more than one-half of this velocity, or 274 miles per second, would be derived from their mutual attraction as they approached each other. We have consequently to assume an original or projected velocity of only 202 miles per second. If the original velocity was 678 per second, this, with the 274 derived from gravity, would generate an amount of heat which would suffice for $200,000,000$ years. And if we assume the original velocity to have been 1,700 miles per second, an amount of heat would be generated in a single moment which would suffice for no less than $800,000,000$ years.

It will be asked, Where did the two bodies get their motion? It may as well, however, be asked, Where did they get their existence? It is just as easy to conceive that they always existed in motion as that they always existed at rest. In fact, this is the only way in which energy could remain in a body without dissipation into space. Under other forms a certain amount of it is constantly being transformed into heat which never can be retransformed back again, but is dissipated into space as radiant heat. But a body moving in void stellar space will retain its energy in the form of motion undiminished and untransformed for ever, unless a collision takes place.

The theory that the sun's heat was originally derived from motion in space is, therefore, for this reason, also more in harmony with evolution than the gravitation theory, because it explains how the enormous amount of energy which is being dissipated into stellar space may have existed in the matter composing the sun untransformed during bygone ages. Or in fact for as far back as the matter itself existed.

In conclusion there are only two sources conceivable from which the sun could have derived his heat. The one is gravitation, the other motion in spaci. The former could have afforded only about $20,000,000$ or $30,000,000$ years' heat, but there is in reality no absolute limit to the amount which may have been derived from the latter source, for the amount generated would depend on the velocity of motion. And when we take into consideration the magnitude of the stellar universe, the difference between a motion of 202 miles per second, and one of 1,700 miles to a great extent disappears, and the one velocity becomes about as probable as the other.

It may be urged as an objection to the theory that we have no experience of bodies moving in space with such enormous velocities as the above. This objection, for the following reason, is of no weight.

No body moving with a velocity exceeding 400 miles per second could remain a member of our solar system; and beyond our system there is nothing visible but the stars and nebulæ. These stars, however, are suns like our own, and visible because, like the sun, they have lost their motion-the lost motion being the origin of their light and heat. Bodies moving in stellar space with these enormous velocities can have neither light nor heat, and, of course, must be invisible to us. Thev must first lose their motion before the kinetic energy in the form of motion can be transformed into light and heat, so as to coristitute visible suns.

JAMES CROTL

\section{ON THE FORWATION OF ITATLSTOVES, RAINDKOPS, HVD SNOWELAKES'}

$T \mathrm{HE}$ author commences by recapitulating some of the leading points in a paper which he read before the same Snciety on October $3 \mathrm{I}, 1876$, "On the Manner in which Raindrops and Hailstones are Formed." In this paper, which was published in NATURE (vol. xvi. p. 163), he had shown that the aggregation of the small cloud particies into raindrops or hailstones is sufficienily accounted for by the fact that the larger purticles descend faster than the others, and consequently overtake those immediately beneath them, and, combining with these, form still larger particles, which move with greater velocity, and more quickly overtaking the particles in front of them, add to their size at an increasing rate. He also showed that the shape and structure of ordinary hailstones was exactly such as would result from this manner of formation. For he had observed that the shape of hailstones was not as it at first sight appeared, that of more or less imperfect spheres, but that of more or less imperfect cones or pyramids with rounded bases, the conical surfaces being striated, the striæ radiating from the vertex; the texture being that of an aggregation of a number of small ice particles without crystalline form, being packed more closely together toward the base or rounded face of the stone. In this paper the author had reverted to the possibility of making artificial hailstones by blowing a stream of frozen fog against a small objecs, making, as it were, the cloud to rise up and meet the stone, instead of the stone falling through the cloud.

He had not, however, then overcome the difficulty of obtaining such a stream of frozen fog, but gave two sketches of plaster stones, which, as far as their shape and the striated appearance of their surface were concerned, closely resembled hailstones, and which plaster stones had been obtained by blowing some finely-divided

I Abstract of paper by Prof. Ostorre Reynolds, F.R.S, read at the Manchester Literary and Philosophical Socicty. 